\title{
Effectiveness of a High School Alcohol Misuse Prevention Program
}

\author{
Jean T. Shope, Laurel A. Copeland, Ruth Maharg, and T.E. Dielman
}

\begin{abstract}
An alcohol misuse prevention curriculum for tenth-grade students was developed, implemented, and evaluated through twelfth grade with 1041 students from four school districts. The curriculum emphasized social pressures resistance training, immediate effects of alcohol, risks of alcohol misuse, and social pressures to misuse alcohol. There were desirable program effects on alcohol misuse prevention knowledge $(p<0.001)$, alcohol misuse $(p<0.02)$, and refusal skills $(p<0.09)$. Gender by occasion differences were found on alcohol use, alcohol misuse, and driving after drinking, with boys' rates increasing more than those of girls. Exposure to a sixth-grade, as well as the tenth-grade, program did not result in better outcomes. Despite high levels of alcohol use among high school students, a tenth-grade curriculum can result in some desirable effects. Creative approaches are needed, however, especially for boys who tend to use and misuse alcohol at rates that increase more steeply than those of girls.
\end{abstract}

Key Words: Adolescents, Gender, Substance Use, School-Based Prevention, Longitudinal Follow-up.

D ESPITE RECENT downturns in reported alcohol use by high school students, ${ }^{1}$ alcohol misuse among young people continues to be a serious problem, too often leading to premature death and injury, especially as a result of driving after drinking. Much effort has been devoted to the development and evaluation of school and community programs to prevent adolescent alcohol misuse. Although traditional approaches have proved disappointing, the social influence model and the generic skills training approach have provided some promising, although limited, results. ${ }^{2,3}$ An intermediate goal of many of the school-based substance abuse prevention programs is improved refusal skills, but these skills are not often assessed.

With the recent, and appropriate, focus on early prevention efforts (elementary and middle school), few prevention programs have targeted high school students (grades 10 to 12). ${ }^{4}$ Several programs targeted eighth- and ninth-grade students, ${ }^{5-7}$ with some modest behavioral effects. The opportunity to develop and evaluate a high school alcohol misuse prevention program arose for the authors in the

From the University of Michigan Transportation Research Institute, Ann Arbor, Michigan.

Received for publication September 15, 1995; accepted February 27, 1996

This study was supponed by the National Institute on Alcohol Abuse and Alcoholism Grants AA 06324 and AA 09026. This work was presented at the Research Society on Alcoholism Annual Scientific Meeting, June 17-22, 1995, Steamboat Springs, Colorado.

Reprint requests: Jean T. Shope, PhD, University of Michigan Transportation Research Institute, 2901 Baxter Road, Ann Arbor, MI, 48109-2150.

Copyright 1096 by The Research Society on Alcoholism. context of evaluating and extending an elementary school curriculum. A booster to the elementary school-based prevention curriculum seemed desirable in tenth grade for both practical and theoretical reasons. Pragmatically, it was the first opportunity (given the combined schedules of grant awards and school years) to use the evaluation results from the elementary curriculum in the development of a tenth-grade booster curriculum. From a theoretical standpoint, tenth graders would be exposed to older students, among whom alcohol use and misuse would be more prevalent. Pressures to use and misuse alcohol would be very real for these students. Also, because a Michigan driver's license can be obtained at age 16, many peers would be drivers and have access to motor vehicles. An intervention to reduce the usual increase in alcohol use, alcohol misuse, and driving after drinking seemed timely. In addition, an assessment of students' alcohol refusal skills, an important focus of the intervention, was conducted.

The goals of the current study were to design, implement, and evaluate a high school-based alcohol misuse prevention curriculum. The objectives of the intervention were to increase students' alcohol misuse prevention knowledge, increase their ability to refuse the offer of an alcoholic drink, and slow their usually increasing rates of alcohol use, alcohol misuse, and driving after drinking. In addition to the effect of the high school curriculum, two other factors were analyzed: gender and prior intervention. Gender was investigated because boys' use of alcohol differs from that of girls. About one-third of the subjects had previously been exposed to a sixth-grade Alcohol Misuse Prevention Study (AMPS) curriculum, affording an opportunity to assess effects of the high school curriculum with and without prior intervention. Previous studies reported the results of the elementary school-based curriculum at 1 -year ${ }^{8,9}$ and 2-year follow-ups. ${ }^{10,11}$

It was hypothesized that students who received the tenthgrade curriculum would have higher alcohol misuse prevention knowledge and refusal skill ability, and lower rates of alcohol use, alcohol misuse, and driving after drinking than students who did not. It was further hypothesized that students who received the tenth-grade curriculum after earlier exposure to the sixth-grade curriculum would show the strongest effects, the later program serving as a booster to the earlier one. This study presents an evaluation of the tenth-grade curriculum's impact on the dependent variables by treatment group and gender 2 years after the 
tenth-grade curriculum and 6 years after the sixth-grade curriculum.

\section{METHODS}

\section{Study Design}

A cohort of students in the graduating class of 1991 had participated in the AMPS project as sixth through eighth graders. The study had assigned public school students in six nonmetropolitan southeastern Michigan districts to pretest/no pretest and curriculum/no curriculum conditions according to a Solomon four-group design. ${ }^{9}$ The study design called for a pretest in early grade 6 , followed by curriculum, late Grade 6 Posttest, late Grade 7 Posttest, and late Grade 8 Posttest. The continuing study design called for an early Grade 10 Pretest of all class of 1991 students in the same districts, followed by curriculum, late Grade 10 Posttest, and late Grade 12 Posttest.

This study focuses on the students in nine high school buildings in four of the school districts. Two districts were excluded because they either did not permit curriculum implementation or did not permit a complete twelfth-grade posttest. Tenth-grade classes within buildings were selected, then assigned (randomly when possible) to curriculum or control (usual school program) conditions. Because of variations in required tenth-grade courses and constraints on high school schedules, decisions about appropriate classes were made with each district and building administrator. In three districts, students who received the curriculum were either a randomly chosen half of the classes in a required course, or the second semester health classes, said to be essentially randomly assigned. In the smallest district $(n=133)$, only students whose teachers volunteered to have the AMPS intervention in their classes received the curriculum. Pretesting of all students with parental consent to participate (99.9\%) occurred in late fall of tenth grade; the curriculum was implemented in winter; and the Grade 10 Posttest occurred 2 months after intervention in spring. The Grade 12 Posttest was administered in spring of twelfth grade. Make-up dates were to be scheduled if absenteeism on the survey day exceeded $15 \%$.

\section{Cuniculum}

A curriculum guide for the tenth grade was developed by the study staff in $1989 .{ }^{12}$ The curriculum was designed to augment knowledge and skills taught in sixth grade, and to give students opportunities to acquire knowledge and skills relevant to tenth graders. Based on social learning theory, the AMPS curriculum taught about alcohol in its social context. Goals of the curriculum (Table 1) included increasing students' awareness of the short-term effects of alcohol, risks of alcohol misuse, and situations and social pressures to misuse alcohol that students might encounter. Students were introduced to skills for dealing with such pressures and situations. Thus, the curriculum attempted to "inoculate" students, ${ }^{13}$ preparing them to cope effectively with peer and other social pressures to misuse alcohol.

The curriculum was presented in five sessions, 45 min each, that were designed to actively involve students and positively reinforce their efforts. Each session was previewed, taught, and summarized. Previous sessions were reviewed. Audiovisual materials, student activity sheets, and handouts added interest. Sessions provided multiple opportunities for students to develop, practice, and observe others using resistance skills in role plays. The curriculum was twice pilot-tested and revised by project staff in a school district that was not in the main study. Finally, seven certified teachers were hired and trained for $16 \mathrm{hr}$ over four consecutive days.

Several procedures assured that the curriculum was implemented as designed. Standardization was emphasized in the teacher training and discussed in weekly staff meetings. Teachers rated their own performance in each session on achievement of the objectives, complete coverage of topics, and an overall good job. Ratings were high, averaging 4.59 on a scale of 1 (not very well) to 5 (very well) over all 355 sessions taught. In addition, a pair of trained raters with high interrater agreement observed and rated an average of 14 sessions per teacher. Ratings on 10 desirable performance objectives (positive feedback, enthusiasm, clear presentation, etc.), each ranging from not at all (1) to always (5), were averaged over all five sessions, giving the teachers an overall mean performance rating of 4.63. The trained raters also assessed the classroom's atmosphere for student responsiveness, cooperation, involvement, task orientation, and freedom from disruption on scales of not at all (1) to always (5). The overall mean was 4.21 .

\section{Data Collection}

Students completed confidential, self-administered questionnaires administered by trained project staff in students' regular classrooms where feasible, otherwise in large meeting rooms. Students' questions were answered in a standardized manncr. Staff assured students that their responses would be confidential, and classroom teachers were asked to position themselves so as not to inhibit or bias the students' responses. Questionnaire data were edited, keypunched, checked for wild codes and within- and across-occasion consistency, and cleaned accordingly.

Assessment of a student's ability to refuse the offer of a mock beer was conducted with a random subset of students at the Grade 10 Posttest Trained raters explained that they would act out a scene at a party wherein the student did not want to drink, but was offered a beer by a friend (played by one rater). After the role play, the student was asked to complete a self-rating form about his/her refusal, while a male and a female rater also completed forms on the student's refusal. Seven items on the forms included an overall sense of how convincing the refusal was, how well it would work in "real life," and items describing body language, eye contact, and voice. ${ }^{14}$

\section{Subjects}

This study defined the sample as being established in tenth grade. Earlier exposure to a sixth-grade prevention curriculum was viewed as a background factor. This permitted study of a larger group of students than would have been possible if presence in the study in sixth grade had been required. Mobility in these suburban communities was high. Moves within study districts occurred in a few cases.

Some information on the initial AMPS subjects might be helpful. In sixth grade, there were 2024 eligible students in the Class of 1991. In tenth grade, 1100 , or $54.3 \%$, of these 2024 students took the 10 th grade survey. Some 59 of the 1100 students did not provide complete data in high school and are therefore not included in the longitudinal sample of 1041. Altogether $744(36.8 \%)$ were not on the records, presumed moved; $116(5.7 \%)$ were absent; and $35(1.7 \%)$ were reported as school drop-outs. Another 29 students $(1.4 \%)$ refused, had a parent refuse, were unavailable, or were reported as moved. New students made up the remaining 931 students $(45.8 \%)$ who participated in the tenth-grade pretest.

The 2031 students who completed Grade 10 Pretest questionnaires comprised $86.1 \%$ of the 2358 eligible tenth-grade students. Absenteeism accounted for $8.5 \%$ of those not surveyed, drop-outs $2.8 \%$, changing schools $1.6 \%$, student refusals $0.7 \%$, student unavailability $0.3 \%$, and parent refusals, 1 case. Of the 2031 pretested students, $1613(79.4 \%)$ completed questionnaires at the Grade 10 Posttest and $1185(58.3 \%)$ did so at the Grade 12 Posttest. A total of 1041 students, or $51.2 \%$ of pretested students, completed all three questionnaires and provided the data that are used herein.

The considerable attrition from Grade 10 Pretest to Grade 12 Posttest was caused by students moving away or dropping out of the study schools over the $2 \frac{1}{2}$-year period $(25.6 \%)$, absenteeism (14.6\%), unavailability $(0.3 \%)$, and student refusal $(1.1 \%)$. Of the 1041 students in the analyzed longitudinal subset, 531 were in the control group (attended no curriculum sessions), and 510 were in the curriculum group (attended at least one session). Most ( $97.5 \%$ ) of the curriculum students attended three or more sessions. The sample of tenth-grade students whose refusal skills were assessed numbered 641; of these, 327 were in the longitudinal sample because they completed all three high school surveys. About one-half (160) of the 327 were exposed to the curriculum intervention. 
Table 1. Alcohol Misuse Prevention Tenth-Grade Curriculum Summary

\begin{tabular}{|c|c|c|}
\hline Session/goal & Objectives & Activity summary \\
\hline $\begin{array}{l}\text { Session } 1 \\
\text { Help students learn/review key facts about } \\
\text { alcohol and its short-term effects, the } \\
\text { risks of drinking and driving, and the } \\
\text { risks of alcohol misuse. }\end{array}$ & $\begin{array}{l}\text { 1. Explain three facts about alcohol and its short-term effects. } \\
\text { 2. Recognize the potential health, social, and legal risks of alcohol } \\
\text { misuse. } \\
\text { 3. Recognize the potential consequences of alcohol misinformation. }\end{array}$ & $\begin{array}{l}\text { Introduction; worksheet done in small } \\
\text { groups; game; poster for class; } \\
\text { pamphlets for each student; } \\
\text { anticipation of next session. }\end{array}$ \\
\hline \multicolumn{3}{|l|}{ Session 2} \\
\hline $\begin{array}{l}\text { Provide students with an understanding of } \\
\text { the concepts group norms, expectations, } \\
\text { and peer pressure, their influence on } \\
\text { behavior, and pressures/influences on } \\
\text { people to drink alcohol. }\end{array}$ & $\begin{array}{l}\text { 1. Identify and define two examples of group norms, applying the terms } \\
\text { expectations and positive and negative outcomes to typical } \\
\text { behaviors. } \\
\text { 2. Identify ways in which peer group norms pressure/influence people } \\
\text { to behave in certain ways because of outcomes that they regard as } \\
\text { positive (group acceptance), but that may also have negative } \\
\text { consequences. } \\
\text { 3. Recognize the different appeals advertising uses to pressure people } \\
\text { to use alcohol. } \\
\text { 4. Identify other pressures/influences on people to use alcohol. }\end{array}$ & $\begin{array}{l}\text { Review; class discussion; } \\
\text { worksheets; transparencies; } \\
\text { conflict situations with questions } \\
\text { for small groups; TV alcohol } \\
\text { advertisements on video; } \\
\text { anticipation of next session. }\end{array}$ \\
\hline \multicolumn{3}{|c|}{ th } \\
\hline $\begin{array}{l}\text { Help students analyze how advertising, role } \\
\text { models, availability of alcohol, and offers } \\
\text { of a drink pressure/influence people to } \\
\text { use alcohol and to recognize that these } \\
\text { pressures/influences, as well as peer } \\
\text { pressure, are based on similar appeals; } \\
\text { help students understand the need to } \\
\text { maintain control over one's own health } \\
\text { and well-being; provide students with } \\
\text { opportunities to analyze typical drinking } \\
\text { situations in terms of the pressures and } \\
\text { outcomes of alcohol use and nonuse. }\end{array}$ & $\begin{array}{l}\text { 1. Understand how role models, availability, offers to drink, advertising, } \\
\text { and peer pressure influence people to use alcohol. } \\
\text { 2. Identify the similar appeals used in all these pressures. } \\
\text { 3. Understand that each person is responsible for his or her own health } \\
\text { and well-being and that the support of friends can be helpful. } \\
\text { 4. Recognize that avoiding potential drinking/driving situations is the } \\
\text { most effective way to reduce one's risk of incurring the negative } \\
\text { consequences associated with drinking/driving. } \\
\text { 5. Anticipate and analyze drinking situations in terms of the pressures } \\
\text { involved and the outcomes of alcohol use and nonuse. }\end{array}$ & $\begin{array}{l}\text { Review; pressure situations } \\
\text { worksheets for small groups; class } \\
\text { discussion; trust walk; booklets for } \\
\text { each student; anticipation of next } \\
\text { session. }\end{array}$ \\
\hline \multicolumn{3}{|l|}{ Session 4} \\
\hline $\begin{array}{l}\text { Provide students with opportunities to } \\
\text { develop and begin using strategies to } \\
\text { resist pressure to use/misuse alcohol in } \\
\text { typical drinking and drinking/driving } \\
\text { situations identified by the students. }\end{array}$ & $\begin{array}{l}\text { 1. Give examples of strategies to resist the pressures of direct offers, } \\
\text { peers, availability, role models, and seeing others drink. } \\
\text { 2. Develop strategies to resist pressure to use/misuse alcohol and to } \\
\text { ride with an impaired driver, and to help friends resist these } \\
\text { pressures in situations similar to those identified in session } 3 \text {. } \\
\text { 3. Begin to use the strategies developed. }\end{array}$ & $\begin{array}{l}\text { Review; class discussion; conflict } \\
\text { situations for discussion. } \\
\text { development, and practice of } \\
\text { resistance strategies; role play } \\
\text { development; anticipation of next } \\
\text { session. }\end{array}$ \\
\hline \multicolumn{3}{|l|}{ Session 5} \\
\hline $\begin{array}{l}\text { Provide students further practice in using } \\
\text { and improving strategies to resist } \\
\text { pressure to drink alcohol and in helping } \\
\text { friends resist pressure in potential } \\
\text { drinking and drinking/driving situations; } \\
\text { provide students with an opportunity to } \\
\text { apply alcohol knowledge and resistance } \\
\text { skills to their own lives. }\end{array}$ & $\begin{array}{l}\text { 1. Demonstrate strategies to resist pressures and to help friends resist } \\
\text { pressures in potential drinking situations. } \\
\text { 2. improve strategies for resistance to offers of alcohol based on } \\
\text { student reactions to and class discussions of the demonstrations. } \\
\text { 3. Demonstrate ability to integrate alcohol knowledge and resistance } \\
\text { skills into their own lives. }\end{array}$ & $\begin{array}{l}\text { Review; role playing; class } \\
\text { discussions; individual worksheets; } \\
\text { closure. }\end{array}$ \\
\hline
\end{tabular}

Attrition from the high school sample was examined for effects on the results. When all of the students in the longitudinal sample $(n=1041)$ were compared with all other students surveyed at Pretest, but for whom complete follow-up data were not available $(n=990)$, several differences were found. There was no significant difference in the proportion of male and female students in each group, but there were significantly fewer Black students than students of other races (self-reported as "White" or "other") in the longitudinal group $(p<0.001)$. Further, at Pretest, the longitudinal group reported means on the dependent variables that were significantly different from those of the lost-to-follow-up group: higher knowledge scores, less alcohol use, less alcohol misuse, and less driving after drinking (all $p$ values $<0.001$ ). There was a significant difference in attrition rates between the two treatment groups, with the curriculum students being more likely to provide longitudinal data than the controls $(p<0.001)$.

\section{Measures}

Alcohol misuse prevention knowledge was measured by 31 items regarding alcohol facts and effects, application of that information to typical alcohol-related situations, pressures to use alcohol, and perceived ability to resist pressure $(\alpha=0.86)$. The percentage of items answered correctly provided each student's knowledge score. ${ }^{14}$

Each student's alcohol refusal skill ability was rated by both female and male raters, in addition to a self-rating. For this study, only the female rating index was used because it had the highest $\alpha$ coefficient $(0.90)$, and during training the female raters showed more consistency across rating occasions and more sensitivity to nonverbal behavior. Ability to refuse the offer of a beer was measured by a 5 -item index. The index resulted from factor analysis of the 7 items on the refusal skill assessment form. Items asked about how convincing the refusal was overall, how persuasive the student's body language was, how much the student's eye contact showed s/he did not want the beer, firmness of voice, and how well the student could refuse in real life. Higher numbers reflected better refusal skill ability (range $=5$ to 20 ). The index showed construct validity in correlation analyses with other study variables. ${ }^{14}$

Students self-reported their alcohol use and misuse. Concerns regarding the validity of adolescents' self-reports of alcohol use, an undesirable behavior, were addressed during pilot testing of the questionnaire in 1984 . 
Results from that study and related evidence on the validity of students' self-reports of substance use with assurance of confidentiality provided confidence in the self-report method used in the study. ${ }^{15-19}$

Frequency and quantity of alcohol use were assessed separately for beer, wine, and liquor. The standardized protocol included a reminder to students that "wine includes wine, wine coolers, and champagne." Frequency of alcohol use was assessed by asking: "How often have you had beer (wine, liquor) in the past 12 months?" Responses to the frequency items were: never $(0)$, a few times a year or less (1), about once a month (2), about once a week (3), 3 or 4 days a week (4), and every day (5). Quantity was assessed with: "When you drank beer (wine, liquor) during the past 12 months, how many cans/bottles (glasses, drinks) did you usually have at one time?" Responses to the quantity items were: none $(0),<$ one drink (1), one drink (2), two drinks (3), 3 or 4 drinks (4), 5 or 6 drinks (5), and seven or more drinks (6). An alcohol frequency/quantity index was created by recoding these data and multiplying frequency times quantity for each substance, then summing the three and dividing to yield total number of drinks per week. This variable was then collapsed to form a 7-point scale reflecting no drinking ( 0 ) to eight or more drinks per week (6). ${ }^{20}$

Alcohol misuse was measured by 10 items assessing the frequency of types of negative consequences experienced as a result of alcohol use during the previous year. The items asked about problems with peers, parents, school personnel, and police, as well as experiences with drinking too much. Sample items include: "During the past 12 months, how many times did you have someone you were dating complain about your drinking?" Responses were collasped to $(0)$ never/(1) once or more, then summed (in the three high school surveys, $\alpha=0.81, .0 .80$, and 0.78 ).

Driving after drinking was assessed by a single questionnaire item. Students were asked: "During the past 12 months, how many times did you drive after drinking?" Responses were: never (0), once (1), two times (2), and three or more times (3).

\section{Data Analysis}

To evaluate the effectiveness of the tenth-grade curriculum on refusal skill ability, analysis of variance (ANOVA) by treatment and gender was used. Variables were assessed for pretest differences by treatment condition. None were found, eliminating the need to use pretest score as a covariate in subsequent analyses. In addition, to determine the relationship between refusal skill ability and knowledge, alcohol use, alcohol misuse, and driving after drinking, Pearson product-moment correlations were calculated for the group as a whole, and for the curriculum and control groups separately.

To evaluate the effectiveness of the tenth-grade curriculum on the other dependent variables, repeated measures ANOVAs were used. The factor of most interest was exposure to the tenth-grade curriculum (two levels). Significant treatment by occasion interactions were of primary interest and would indicate differential rates of change between the treatment groups which, if in the desired direction, would support the effectiveness of the curriculum. Three-way repeated-measures ANOVAs were used to test for differential curriculum effects either by gender (two levels) or by exposure to the sixth-grade curriculum (two levels). Where significant interactions were found, post-hoc comparisons among the means were done, using Scheffé's correction for joint confidence intervals with a criterion $p$ value of 0.05 .

\section{RESULTS}

Repeated-measures ANOVA on the knowledge score (Table 2, Fig. 1) resulted in a significant treatment by occasion interaction effect $(F=29.05,2 / 2066 d f, p<0.001)$, with no effect of gender or sixth-grade curriculum. Post-hoc $t$ tests showed that the curriculum group scored signifi- cantly higher than the control group at both the Grade 10 $(p<0.001)$ and Grade 12 Posttests $(p<0.027)$.

Significant correlations between tenth-grade refusal skill ability and tenth-grade alcohol misuse prevention knowledge, alcohol use, and alcohol misuse were found and reported earlier for a larger sample. ${ }^{14}$ For this study, tenthgrade refusal skill ability scores were found to correlate significantly with the dependent variables at both tenth and twelfth grades (Table 3). At tenth grade, refusal skill correlated positively with knowledge and negatively with alcohol misuse and driving after drinking. At twelfth grade, refusal skill correlated positively with knowledge and driving after drinking. At both grades, the negative correlation with alcohol use was nearly significant. Among the curriculum students only, there were no significant correlations between refusal skill and twelfth-grade measures. Among control students, however, there was a significant negative correlation between refusal skill and driving after drinking $(r=-0.20)$.

Overall, students who experienced the AMPS tenthgrade curriculum $\sim 2$ months earlier were rated slightly higher on their refusal skill ability (mean $=15.46)$ at Grade 10 Posttest than control students (mean $=15.00$ ). In the ANOVAs, a gender by occasion interaction appeared $(F=$ $123.04,1 / 322 d f, p<0.001$ ), with girls' refusal skill rated higher than boys' and a noticeable trend toward an effect of the tenth-grade curriculum $(F=3.43,1 / 323 d f, p<0.087)$. No significant effect of the sixth-grade curriculum was seen.

Repeated-measures ANOVA on alcohol use (Table 2) resulted in a gender by occasion interaction $(F=4.24$, $2 / 1846 d f, p<0.015$ ). Control boys used significantly more alcohol than curriculum girls in post-hoc analysis. The sixth-grade curriculum had no significant effect on high school alcohol use.

Alcohol misuse (Table 2, Fig. 2) showed both treatment by occasion and gender by occasion interactions (treatment, $F=4.06,2 / 1910 d f$, $p<0.017$; gender, $F=3.74$, $2 / 1910 d f, p<0.024)$. Post-hoc, the control group as a whole reported more alcohol misuse at the Grade 12 Posttest than the curriculum group $(t=2.03, p<0.043)$. There were no significant differences among the four groups (gender by treatment). In analyses, including exposure to the sixthgrade curriculum, there was an effect of sixth-grade curriculum over time ( $F=5.74, p<0.003)$, and there was a trend evident of an effect of the tenth-grade curriculum ( $p$ $<0.079$ ), driven by the Grade 10 curriculum students scoring significantly lower than the no-curriculum students. No other pairs were significant in the post-hoc comparisons.

Driving after drinking appeared unresponsive to the high school curriculum $(F=2.12,2 / 1908 d f, p<0.120)$. There was a gender by occasion interaction $(F=5.45,2 / 1908 d f$, $p<0.004$ ), with control boys driving after drinking significantly more often than both the control and treatment girls at the Grade 12 Posttest. The interaction term was not significant. When the sixth-grade curriculum was included in the analyses, that exposure showed a significant effect ( $F$ 


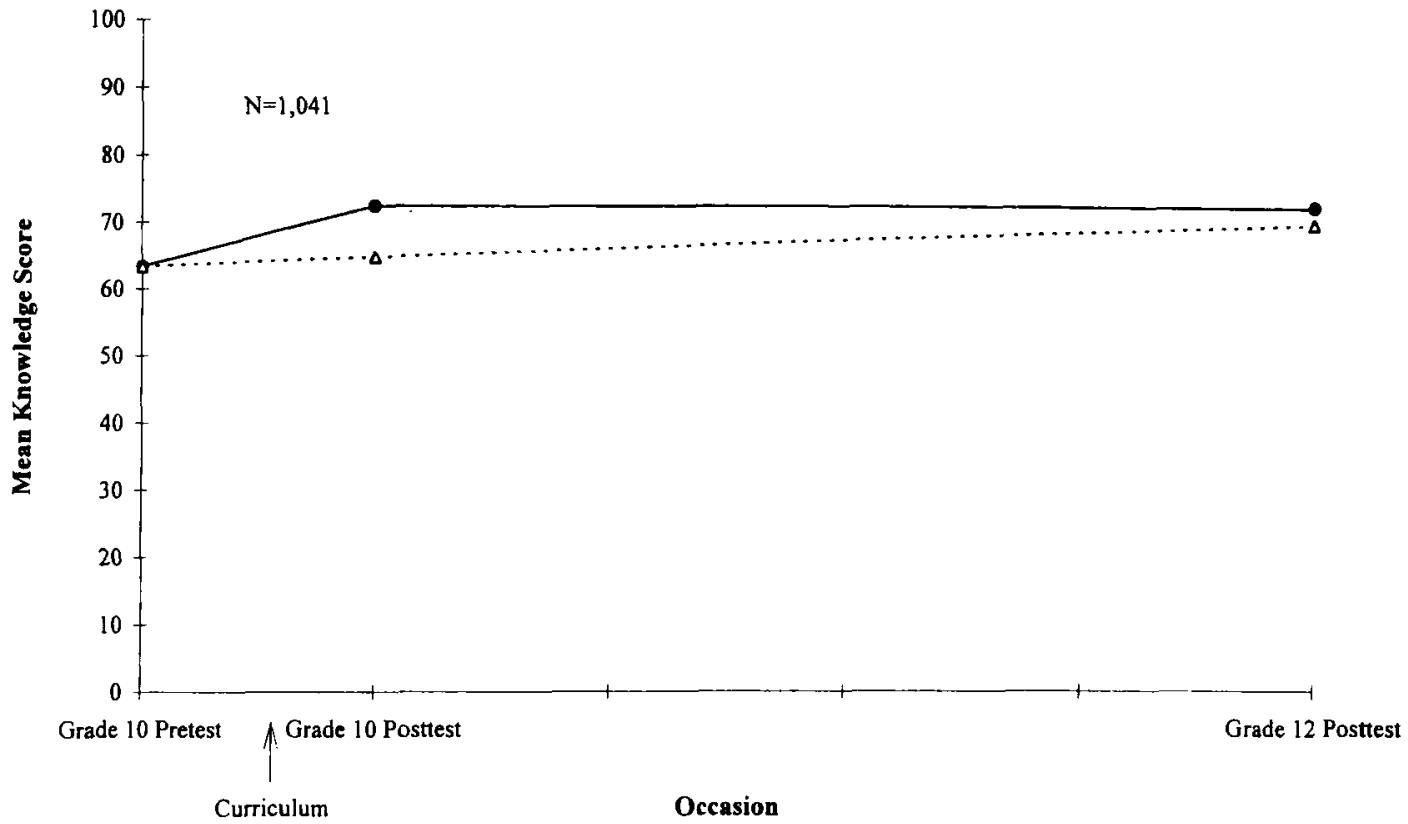

Fig. 1. Alcohol misuse prevention knowledge in a cohort of high school students by treatment group and occasion. $\bullet$, cumiculum group $(n=510) ; \Delta$, control group $(n=531)$.

$=3.89,2 / 1914 d f, p<0.021)$. Post-hoc analyses, however, failed to pinpoint any pair of significantly different means.

\section{DISCUSSION}

This study found that a high school skills-based curriculum could measurably impact students' knowledge and behavior at both immediate and 2-year follow-up posttests. As hypothesized, the curriculum significantly and positively affected alcohol misuse prevention knowledge, and restrained the rate of increase of alcohol misuse. Curriculum effects, although significant, were small, clearly mandating the expansion of intervention efforts.

Among other things, the curriculum taught refusal of the offer of a drink. This refusal skill ability increased slightly in curriculum students, and was positively related to knowledge and negatively related to alcohol use and misuse (including driving after drinking) at both Grade 10 and Grade 12 Posttests. These negative correlations were most pronounced among the control students who went without the benefit of the curriculum.

This study's design allowed for examination of the impact of the high school intervention, with and without a previous sixth-grade intervention. Contrary to the hypothesis, the evidence herein suggests that the earlier intervention did not augment the effect of the high school curriculum, likely caused by effect decay, ${ }^{21}$ combined with the impact of considerable attrition..$^{22}$ Furthermore, a high school program alone can have positive results. Overall, these modest curriculum effects were positive and evident, despite the limitations and challenges faced by the study.

Considerable attrition from the longitudinal sample was one such limitation, the effects of which cannot be known exactly. It is likely, however, that the curriculum's effectiveness could have been demonstrated more clearly had more students been available to follow-up. Specifically, the students who had, at the Grade 10 Pretest, reported lower levels of alcohol misuse prevention knowledge, and higher levels of alcohol use, alcohol misuse, and driving after drinking, were too often those who ultimately gave incomplete longitudinal data. This observation, in addition to the fact that more study subjects were lost from the control group, makes it possible that had attrition been less, the scores of the control group would have been more exaggerated, making the curriculum's effectiveness clearer.

A major cause of attrition was absenteeism. One reason for absenteeism was discovered during data collection. In the spring, some students, especially seniors, cut classes at an unexpectedly high rate, because they knew there would be no penalty for doing so. When absenteeism rates turned out to be high $(>15 \%)$, study staff requested a make-up day. Generally, both administrators and teachers opposed make-up days, feeling that enough time had already been spent on the survey process. Occasionally, attempting to schedule a make-up date for a survey led to less subsequent cooperation from a school. To reduce this opposition, researchers could initially present a survey as taking 3 days: one general day and two make-up days. Absentees could be surveyed through individually arranged meetings at school on later dates, during students' free hours if possible. In longitudinal studies, it would be advisable to include funding for extensive tracking and long-distance interviewing. ${ }^{23}$ The condition of having moved out of the study area would need to be coded for each student and included in analyses. All such efforts, although decreasing attrition, would 
Table 2. Means, Standard Deviations, and Results for Knowledge, Refusal Skills, and Substance Use Measures by Treatment Group, Gender, and Occasion $(n=1,041)$

\begin{tabular}{|c|c|c|c|c|c|c|}
\hline \multirow[b]{2}{*}{$\begin{array}{c}\text { Measure/occasion } \\
n\end{array}$} & \multicolumn{3}{|c|}{ Curriculum mean (SD) } & \multicolumn{3}{|c|}{ Control mean (SD) } \\
\hline & $\begin{array}{l}\text { Total } \\
507\end{array}$ & $\begin{array}{l}\text { Boys } \\
260\end{array}$ & $\begin{array}{l}\text { Girls } \\
247\end{array}$ & $\begin{array}{c}\text { Total } \\
530\end{array}$ & $\begin{array}{c}\text { Boys } \\
273\end{array}$ & $\begin{array}{l}\text { Girls } \\
257\end{array}$ \\
\hline \multicolumn{7}{|l|}{ Knowledge" } \\
\hline \multirow[t]{2}{*}{ Grade 10 Pretest } & 63.4 & 61.9 & 65.2 & 63.4 & 60.7 & 66.2 \\
\hline & $(17.0)$ & (18.5) & $(15.0)$ & $(19.0)$ & $(20.4)$ & $(17.1)$ \\
\hline \multirow[t]{2}{*}{ Grade 10 Posttest $†$} & 72.3 & 70.5 & 74.5 & 64.8 & 61.6 & 68.0 \\
\hline & $(18.5)$ & $(19.7)$ & $(16.6)$ & $(21.0)$ & $(22.7)$ & (18.3) \\
\hline \multirow[t]{2}{*}{ Grade 12 Posttest $†$} & 71.8 & 70.5 & 73.4 & 69.3 & 67.7 & 71.0 \\
\hline & $(18.4)$ & $(20.5)$ & $(15.7)$ & $(17.7)$ & $(18.9)$ & $(16.0)$ \\
\hline \multicolumn{7}{|l|}{ Refusal skills $\ddagger$} \\
\hline \multirow[t]{2}{*}{ Grade 10 Posttest } & 15.46 & 14.86 & 16.15 & 15.00 & 14.35 & 15.53 \\
\hline & $(2.81)$ & (2.63) & $(2.90)$ & $(3.18)$ & $(3.45)$ & $(2.85)$ \\
\hline \multicolumn{7}{|l|}{ Alcohol use§ } \\
\hline \multirow[t]{2}{*}{ Grade 10 Pretest } & 1.98 & 1.99 & 1.95 & 1.98 & 2.05 & 1.92 \\
\hline & $(1.95)$ & $(2.05)$ & $(1.84)$ & (1.99) & $(2.11)$ & $(1.86)$ \\
\hline \multirow[t]{2}{*}{ Grade 10 Posttest } & 2.12 & 2.20 & 2.06 & 2.11 & 2.25 & 1.98 \\
\hline & $(2.00)$ & (2.11) & $(1.89)$ & $(1.97)$ & $(2.08)$ & $(1.86)$ \\
\hline \multirow[t]{2}{*}{ Grade 12 Posttest } & 2.71 & 2.89 & 2.53 & 2.87 & 3.10 & 2.65 \\
\hline & $(2.11)$ & $(2.22)$ & $(1.99)$ & $(2.12)$ & $(2.14)$ & $\langle 2.07\rangle$ \\
\hline \multicolumn{7}{|l|}{ Alcohol misuse" $\S$} \\
\hline \multirow{2}{*}{ Grade 10 Pretest } & 1.63 & 1.53 & 1.73 & 1.58 & 1.52 & 1.64 \\
\hline & $(2.03)$ & $(1.97)$ & $(2.06)$ & $(2.09)$ & $(2.16)$ & $(2.02)$ \\
\hline \multirow[t]{2}{*}{ Grade 10 Posttest } & 1.75 & 1.62 & 1.91 & 1.73 & 1.89 & 1.57 \\
\hline & $(2.09)$ & $(2.04)$ & (2.13) & $(2.18)$ & $(2.41)$ & (1.91) \\
\hline \multirow[t]{2}{*}{ Grade 12 Posttest? } & 2.12 & 2.12 & 2.12 & 2.41 & 2.61 & 2.21 \\
\hline & $(2.08)$ & (2.09) & (2.06) & (2.32) & $(2.40)$ & $(2.24)$ \\
\hline \multicolumn{7}{|l|}{ Driving after Drinking $\S$} \\
\hline \multirow[t]{2}{*}{ Grade 10 Pretest } & 0.09 & 0.10 & 0.08 & 0.10 & 0.11 & 0.09 \\
\hline & $(0.44)$ & $(0.47)$ & $(0.41)$ & $(0.46)$ & $(0.49)$ & $(0.44)$ \\
\hline \multirow[t]{2}{*}{ Grade 10 Posttest } & 0.16 & 0.19 & 0.13 & 0.13 & 0.19 & 0.07 \\
\hline & $(0.59)$ & $(0.63)$ & $(0.54)$ & $(0.50)$ & $(0.61)$ & $(0.36)$ \\
\hline \multirow[t]{2}{*}{ Grade 12 Posttest\# } & 0.60 & 0.68 & 0.52 & 0.69 & 0.83 & 0.55 \\
\hline & $(1.02)$ & $(1.07)$ & $(0.97)$ & $(1.10)$ & (1.19) & $(1.00)$ \\
\hline
\end{tabular}

- Treatment by occasion interaction, $p<0.05$.

$\dagger$ Per post-hoc $t$-test, Curriculum Students scored higher than Control Students, $p<0.05$.

$\ddagger$ Curriculum Students scored higher than Control Students, $p<0.10$. Girls scored higher than boys, $p<0.05$. This measure was assessed at Grade 10 Posttest only. $n$ 's are: Curriculum, 159 total- 87 males, 72 females; Control, 167 total- 75 males, 92 females.

$\S$ Gender by occasion interaction, $p<0.05$.

7 Per post-hoc $t$ test, Curriculum Students scored lower than Control Students, $\rho<0.05$.

\# Per post-hoc ANOVA, Curriculum Girls scored lower than Control Boys, $p<0.05$.

greatly increase data collection costs. It is hoped, however, that the benefit to study validity could be persuasive.

As is apparent from the reported study methodology, maintaining a research study and delivering an intervention in nine high schools presented many challenges beyond attrition. Randomization for receipt of the tenth-grade curriculum was not entirely successful. The prevention curriculum and the survey administration were difficult to schedule, particularly with high school seniors. Communication about the study through administrators and teachers to the students varied considerably by school, and may have affected students' attitudes toward the survey in some cases.

Nonetheless, the results demonstrated that high school students' knowledge and behavior related to alcohol can be modestly improved, as a few others have also found. Newman et al., ${ }^{6}$ at a 1-year follow-up of a small cohort of students, found that knowledge, perceived ability to resist pressures, and riding with a drinking driver were improved among experimental students, although alcohol use was unchanged. In a small study with some methodological limitations, ${ }^{24}$ Collins and Cellucci ${ }^{4}$ reported positive effects on knowledge, but not on attitudes or alcohol involvement 1 month after an alcohol education program delivered to tenth- and eleventh-grade students. Duryea ${ }^{5}$ and Duryea et al. ${ }^{25}$ found positive knowledge, attitude, skill, and behavioral effects after an alcohol education program targeting ninth-grade students. Perry and $\mathrm{Grant}^{7}$ reported positive results on alcohol use 2 months after a peer-led, social influences, alcohol education program delivered to 13- and 14-year-olds.

Several implications for practitioners implementing alcohol misuse prevention programs for young people can be

Table 3. Correlations Among Refusal Skill Ratings and Measures of Misuse Prevention Knowledge, Alcohol Use, Alcohol Misuse, and Driving after Drinking

\begin{tabular}{lcccc}
\hline & $\begin{array}{c}\text { All students } \\
\text { grade 10 }\end{array}$ & $\begin{array}{c}\text { All students } \\
\text { grade 12 }\end{array}$ & $\begin{array}{c}\text { Curriculum } \\
\text { students } \\
\text { grade 12 }\end{array}$ & $\begin{array}{r}\text { Control } \\
\text { students } \\
\text { grade 12 }\end{array}$ \\
\hline Knowledge & $0.16^{* *}$ & $0.13^{* *}$ & 0.12 & $0.14^{*}$ \\
Alcohol use & $-0.11^{*}$ & $-0.11^{*}$ & -0.09 & -0.12 \\
Alcohol misuse & $-0.15^{* *}$ & $-0.11^{*}$ & -0.08 & -0.12 \\
Driving after drinking & $-0.11^{* *}$ & $-0.12^{* *}$ & -0.00 & $-0.20^{* *}$ \\
\hline
\end{tabular}

$p$ values are as follows: " $p<0.07 ; " * p<0.05$. 


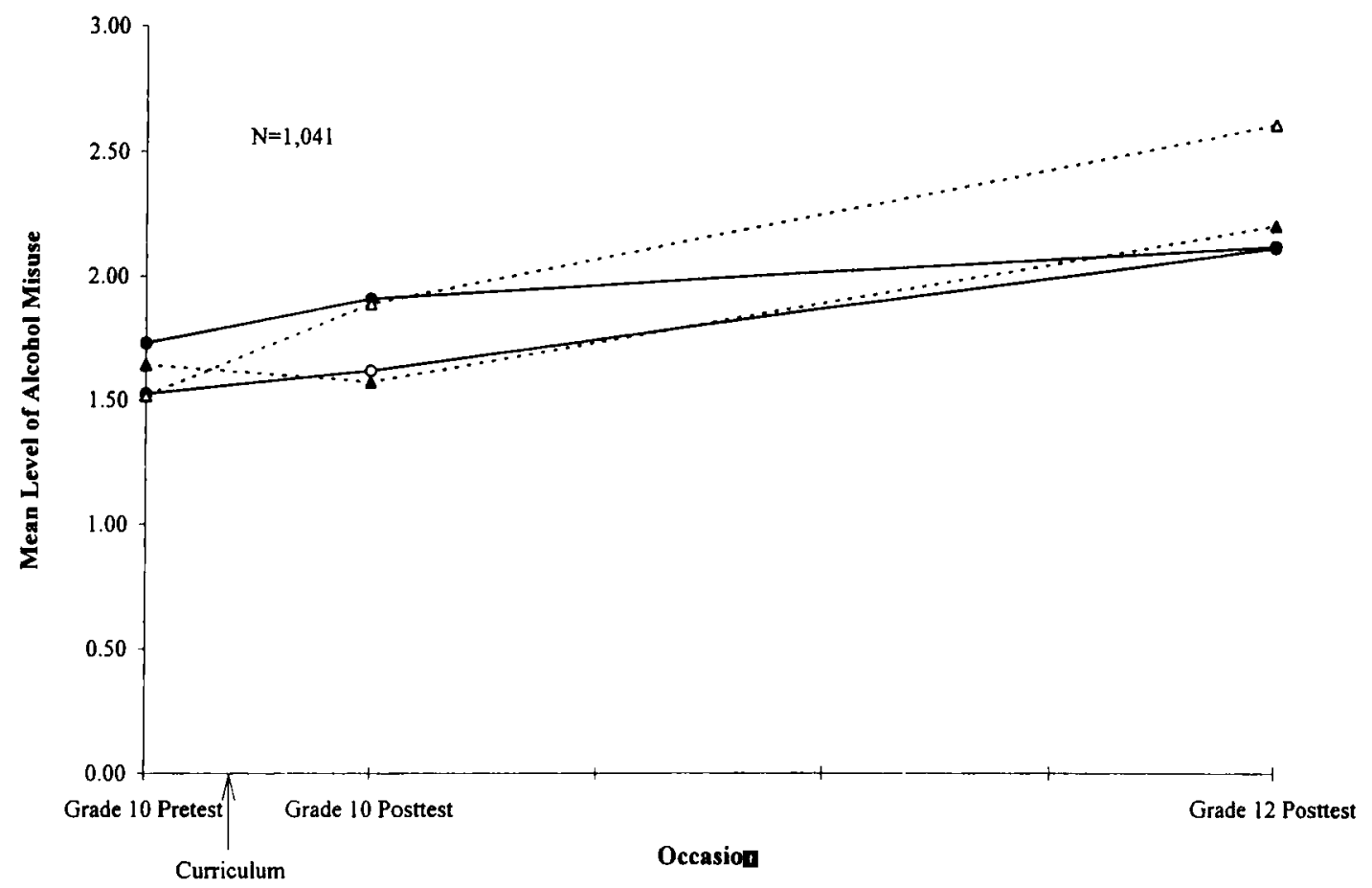

Fig. 2. Alcohol misuse in a cohort of high school students by treatment group, gender, and occasion. $O$, curriculum boys $(n=240) ; \bullet$, curriculum girls $(n=236)$; $\Delta$, control boys $(n=240) ; \Delta$, control girls $(n=243)$.

drawn from this and other reports. Throughout these analyses, the impact of gender is seen. In designing interventions, therefore, the differing needs of boys and girls should be accommodated. Also, although positive high school prevention results have been obtained, prevention should start much earlier. Yet, the positive effects of earlier prevention efforts have been found to dissipate, probably within 2 years. ${ }^{21}$ It would seem, then, that the best approach is to present a developmentally appropriate alcohol misuse prevention program at several consecutive grade levels, recognizing that young people will respond at different ages to different approaches, information, and social skills training. The ability to resist ongoing societal pressure to use and misuse alcohol must be taught, like mathematics and reading, continuously. True change in the norms and long-term outcomes of alcohol use cannot otherwise be expected.

Given the modest success of school-based program evaluations reported to date, innovative approaches to prevention must be developed and implemented. Simons-Morton et al. ${ }^{26}$ suggest an ecological approach toward the prevention of drunk driving injuries among youth, which would provide a framework for diagnosing the problem and planning interventions at different levels. The risk-focused approach for substance abuse prevention described by Hawkins et al. ${ }^{27}$ may hold promise, because developmental conditions experienced by children, although impossible to affect through school-based programs, could be addressed, especially for high-risk youth.

In addition to more rigorous school-based efforts targeting social influences and refusal skills, broad-based prevention approaches are needed. Community-wide interven- tions that establish safer norms and social support for adolescents' nondrinking behavior need to be undertaken. Family-based interventions could link the communitybased efforts with the school-based work. Such new preventive interventions will need to be carefully evaluated over an adequate period of time. The study reported herein provides a basis for understanding some of the variables that were positively affected by a school-based social influences program and encouragement for the teaching of alcohol refusal skills. Expansion in these prevention areas-driving after drinking, managing offers of alcohol, and avoiding alcohol misuse-beckons to the innovator.

\section{REFERENCES}

1. Johnston LD, O'Malley PM, Bachman JG: National Survey Results on Drug Use from the Monitoring the Future Study, 1975-1994 (Volume I: Secondary School Students). NIH 95-4026. Rockville, MD, Nationa] Institute on Drug Abuse, 1995

2. Botvin GJ, Botvin EM: Adolescent tobacco, alcohol, and drug abuse: Prevention strategies, empirical findings, and assessment issues. J Dev Behav Pediatr 13:290-301, 1992

3. Perry CL, Kelder SH: Models for effective prevention. J Adolesc Health 13:355-363, 1992

4. Collins D, Cellucci T: Effects of a school-based alcohol education program with a media prevention component. Psych Rep 69:191-197, 1991

5. Duryea EJ: Utilizing tenets of inoculation theory to develop and evaluate a preventive alcohol education intervention. J Sch Health 53: $250-256,1983$

6. Newman IM, Anderson CS, Farrell KA: Role rehearsal and efficacy: Two 15-month evaluations of a ninth grade alcohol education program. J Drug Educ 22:55-67, 1992

7. Perry CL, Grant M: A cross-cultural pilot study on alcohol education and young people. World Health Stat Q 44:70-73, 1991

8. Dielman TE, Shope JT, Butchart AT, Campanelli PC: Prevention 
of adolescent alcohol misuse: An elementary school program. J Pediatr Psychol 11:259-282, 1986

9. Dielman TE, Shope JT, Campanelli PC, Butchart AT: Elementary school-based prevention of adolescent alcohol misuse. Pediatrician 14:7076, 1987

10. Dielman TE, Shope JT, Leech SL, Butchart AT: Differential effectiveness of an elementary school-based alcohol misuse prevention program. J Sch Health 59:255-263, 1989

11. Shope JT, Dielman TE, Butchart AT, Campanelli PC: An elementary school-based alcohol misuse prevention program: Follow-up evaluation. J Stud Alcohol 53:106-120, 1992

12. Shope JT, Dielman TE, Maharg R, Leech SL, Miller, M: Alcohol Misuse Prevention: Booster Curriculum Guide for Tenth-Grade. Ann Arbor, University of Michigan, 1989

13. Evans RJ: Smoking in children: Developing a social psychological strategy of deterrence. Prev Med 5:122-127, 1976

14. Shope JT, Copeland LA, Maharg R, Dielman TE, Butchart BA: Assessment of adolescent refusal skills in an alcohol misuse prevention study. Health Educ Q 20:373-390, 1993

15. Campanelli PC, Dielman TE, Shope JT: Validity of adolescents' self-reports of alcohol use and misuse using a bogus pipeline procedure. Adolescence 22:7-22, 1987

16. Akers R, Massey J, Clark W, Lauer R: Are self-reports of adolescent deviance valid? Biochemical measures, randomized response, and the bogus pipeline in smoking behavior. Soc Forces 62:234-251, 1983

17. O'Malley P: Cigarette smoking among high school seniors. Did the rate decline? Prev Med 13:421-426, 1984

18. O'Malley P, Bachman J, Johnston L: Reliability and consistency in self-reports of drug use. Int J Addict 18:805-824, 1983
19. Hansen W, Malotte C, Fielding J: The bogus pipeline revisited: The use of the threat of detection as a means of increasing self-reports of tobacco use. J Appl Psychol 70:789-792, 1985

20. Shope JT, Copeland LA, Dielman TE: The measurement of alcohol use and misuse in a cohort of students followed from grade 6 through grade 12. Alcohol Clin Exp Res 18:726-733, 1994

21. Ellickson PL, Bell RM, McGuigan K: Preventing adolescent drug use: Long-term results of a junior high program. Am J Public Health 83:856-861, 1993

22. Donaldson SI, Graham JW, Hansen WB: Testing the generalizability of intervening mechanism theories: Understanding the effects of adolescent drug use prevention interventions. J Behav Med 17:195-216, 1994

23. Pirie PL, Thompson SJ, Mann SL, Peterson AV Jr, Murray DM, Flay BR, Best JA: Tracking and attrition in longitudinal school-based smoking prevention research. Prev Med 18:249-256, 1989

24. Duryea EJ: Psychometric and related deficits in preventive alcohol intervention programming. Psych Rep 70:333-334, 1992

25. Duryea E, Mohr P, Newman IM, Martin GL: Six-month follow-up results of a preventive alcohol education intervention. J Drug Educ 14: 97-104, 1984

26. Simons-Morton BG, Brink SG, Simons-Morton DG, McIntyre RM, Chapman M, Longoria J, Parcel GS: An ecological approach to the prevention of injuries due to driving after drinking. Health Educ $Q$ $16: 397-411,1989$

27. Hawkins JD, Catalano RF, Miller JY: Risk and protective factors for alcohol and other drug problems in adolescence and early adulthood: Implications for substance abuse prevention. Psychol Bull 112:64-105, 1992 